\title{
Aerosol Particles Generated by Coughing and Sneezing of a SARS-CoV-2 (COVID-19) Host Travel over 30 m Distance
}

Special Issue:

Special Issue on COVID-19 Aerosol Drivers, Impacts and Mitigation (XI)

\author{
Boris Gorbunov ${ }^{1,2 *}$ \\ ${ }^{1}$ Ancon Technologies Ltd., CIC, Canterbury, Kent CT2 7FG, UK \\ ${ }^{2}$ Ancon Medical Inc., Bloomington, Minneapolis, Minnesota, USA
}

Keywords: COVID-19 transmission, Viral load, Size distribution, Modelling

\section{INTRODUCTION}

\section{OPEN ACCESS}

Received: July 30, 2020

Revised: November 26, 2020

Accepted: December 5, 2020

${ }^{*}$ Corresponding Author:

boris.gorbunov@anconmedical.com

\section{Publisher:}

Taiwan Association for Aerosol Research

ISSN: $1680-8584$ print ISSN: 2071-1409 online

\section{Copyright: The Author(s).} This is an open access article distributed under the terms of the Creative Commons Attribution License (CC BY 4.0), which permits unrestricted use, distribution, and reproduction in any medium, provided the original author and source are cited.
Understanding transmission of COVID-19 infection is one of the key issues the scientific community faces. Investigating the main virus transmission routes is vital for policy development to curb the spread of the current pandemic. The US Centres for Disease Control and Prevention recommends a 6 -foot $(1.83 \mathrm{~m}$ ) separation distance. This exclusion distance is based on estimates of the range that have not considered convection flow and atmospheric diffusivity that affect dispersion of exhaled aerosol clouds considerably. Recent works on COVID-19 have shown that sneezes and coughs not only consist of large mucosalivary droplets that quickly follow shortrange deposition trajectories downwards but, importantly, are primarily made of a multiphase turbulent gas (a puff) cloud that entrains ambient air and carries aerosol particles (Bourouiba, 2020).

The initial stage of airborne viral disease transmission is caused by virus laden droplets that are generated mainly by coughing, sneezing (Jayaweeraa et al., 2020; Mittal et al., 2020). This creates a population of airborne particles in the vicinity of a host. There is an ambiguity about terminology used for these particles: in some publications they are described as droplets, but in others as aerosol particles (Yang et al., 2007; Vuorinen et al., 2020). Here to avoid an ambiguity, airborne particles (diameter $<100 \mu \mathrm{m}$ ) generated by infected persons are described as aerosol particles assuming that these include other terms such as droplets, microdroplets and nuclei with and without viruses (Pruppacher and Klett, 1997; Baron and Willeke, 2001).

There are two major routes whereby infection can be transmitted from a host to another person: first, viruses are directly transmitted through the air by aerosol particles that are inhaled into the oronasopharynx and second, an indirect transmission when viruses are transferred by contact with contaminated objects (Pica and Bouvier, 2012; Mittal et al., 2020). Respiratory 
infectious diseases can be spread by airborne transmission (Hui, 2010; Rosa et al., 2013; Jin et al., 2020; Morawska and Cao, 2020). Airborne routes seem to be important for spreading COVID19 for both presymptomatic and asymptomatic individuals (Domingo et al., 2020; Eissenberg and Shihadeh, 2020; Howard et al., 2020; Setti et al., 2020a). The presence of COVID-19 (SARS-CoV-2) virus on particulate matter have been confirmed in Northern Italy (Setti et al., 2020b) and in China (Liu et al., 2020).

van Doremalen et al. (2020) evaluated the stability of SARS-CoV-2 and SARS-CoV-1 in aerosols and on various surfaces and estimated their decay rates. SARS-CoV-2 remained viable in aerosols throughout the duration of the experiment ( 3 hours). Their results indicate that aerosol transmission of SARS-CoV-2 (COVID-19) is plausible, since the virus can remain viable and infectious in aerosols for hours and on surfaces up to days. On the contrary, Xiao et al. (2020) stated that evidence from some trials did not support a substantial effect on transmission of laboratory-confirmed influenza via the aerosol route. The complexity of experimental data on COVID-19 in field and laboratory fuels interests to modelling aerosol particles transmission in both open spaces and confined environments.

Recently a number of works on modelling aerosol transport in relation to SARS-CoV-2 transmission have been published. For example, a computational fluid-particle dynamics (CFPD) model was employed to simulate the transport, condensation/evaporation, and deposition of SARS-CoV-2 laden droplets emitted by coughs, with different wind velocities and humidity in a small 3 m cube (Feng et al., 2020). Numerical results indicate that the convection will enhance the complexity of the secondary flows with recirculation between the two virtual humans in the cube. With the complex environmental wind and relative humidity $(\mathrm{RH})$ conditions, the 6-feet social distancing policy may not be sufficient to protect the direct person-to-person aerosol transmission.

Four different 3D computational fluid dynamics (CFD) simulation software were employed to investigate the effect of air ventilation on aerosol evolution in indoor environment (Vuorinen et al., 2020). They show that the exposure time to inhale $>100$ aerosol particles could range from seconds to hours depending on the situation.

The COVID-19 pandemic has exposed significant scientific gaps in our understanding of critical issues, ranging from the transmission pathways of such respiratory diseases, to the strategies used for mitigating these transmissions (Feng et al., 2020; Jayaweeraa et al., 2020; Mittal et al., 2020; Morawska and Cao, 2020). Discrepancies in collected data suggest that more research is necessary to determine with increased certainty the role that environmental factors play in the transmission of viral pathogens exhaled by infected individuals.

In this paper, methods of atmospheric physics well developed for air quality modelling are employed to evaluate importance of the aerosol route for COVID-19 transmission. Here we are considering aerosol dispersion in complex geometries by employing compressible Navier-Stokes equations, with an integrated turbulent diffusion, aerosol-gas mass exchange, heat transfer with gravitational forces and buoyancy. The aerosol exposure-dose relationship will be investigated using the International Commission on Radiological Protection (ICRP) lung deposition model (ICRP, 1994). The main aim of this work is to: a) reduce uncertainties associated with aerosol transmission of COVID-19 in public places and evaluate the travel distances of larger particles (inertial size range) under typical conditions for different geometries; b) quantify effects of heat transfer on aerosol dispersion; c) investigate exposure-dose relationships for aerosol particles of relevant sizes and d) consider possible metrics for quantification of the risk mitigation associated with exposure to virus laden aerosols.

\section{MODELLING OF COVID-19 SPREAD VIA THE AIR}

The aerosol transformation processes relevant to dispersion of SARS-CoV-2 viruses were studied employing validated Comsol v5.5 finite element software (see ref. Comsol Multiphysics and Steer et al., 2014). The software comprises the Fluid Dynamics module with Navier-Stokes compressible flow (Ma < 0.3) equations, Heat Transfer module and Transport of Diluted Species with atmospheric turbulent diffusion module. These modules were solved together using Comsol Multiphysics software. It should be noticed that both Comsol versions of Navier-Stokes equations 
(compressible and incompressible) can be employed here because they produce identical results for the problems solved here.

The Navier-Stokes equations especially combined with heat and mass transfer are notoriously difficult for numerical modelling. The modelling procedure involves a set of software runs with different mesh sizes starting from coarse towards finer meshes until the mesh refinement does not influence the result. Both global and local mesh refinement metric were used to ensure efficiency of convergence and accuracy of the solution. A local metric is defined at a specific location in the model but the global - over the entire model space. The Mesh Builder module automatically generates non-uniform meshes with smaller sizes near sharp corners or surfaces with small curvature radius.

The PARDISO direct solver and iterative GMRES solver have been employed for stationary and time dependent velocity fields $(u, v, w, t)$, temperature field $T_{X, Y, Z, t}$ and the number concentration of aerosol particles $C_{X, Y, Z, t}$. An additional mass transfer of water vapor between aerosol particles and the gas phase was simplified and employed as a parameterization of a direct modelling of the mass exchange (Pruppacher and Klett, 1997; Baron and Willeke, 2001; Vuorinen et al., 2020). The lung deposition model was based on ICRP (1994) with lung deposition efficiency from Gorbunov et al. (2004); Ruzer et al. (2005); Karl et al. (2016).

In modelling, the dispersion of the aerosol cloud was calculated from a simplified initial aerosol cloud of an elliptical shape with a given aerosol number concentration and cloud boundaries. The subsequent evolution of the aerosol particles concentration was recorded as a concentration $C_{X, Y, Z}$ for a steady-state modelling or as $C_{X, Y, Z, t}$ for time dependent solutions.

In this work we developed a simple human head model where we used a cylinder for neck and ellipsoids for the head and nose. This model is a useful simplification. We tested how variations in the size of the model and features of the head affect the aerosol concentration field. It was found that variation in size of parts (by $10 \%$ ) has less than $1 \%$ influence on the aerosol/droplet concentration at distances more than $2 \mathrm{~m}$ from the source. Therefore, the simplified human model seems to be enabled to obtain sufficiently accurate results.

\subsection{Steady-state Aerosol Source X-Z Plane and Boundary Conditions}

First, an open space aerosol dispersion 2D steady-state model was developed and employed to evaluate the influence of the wind velocity on the possibility of transferring aerosol particles from the source to an uninfected person. In the model, aerosol particles of sizes close to those observed in coughing, talking and sneezing experiments were considered. The concentration field of aerosol particles $\left(C_{X, Z}\right)$ have been calculated in $X-Z$ space $(-3 \mathrm{~m}<\mathrm{X}<17 \mathrm{~m} ;-2.5 \mathrm{~m}<\mathrm{Z}<$ $2.5 \mathrm{~m}$ ). The mouth of the host head was at $X=0, Z=0.8 \mathrm{~m}$ or $1.7 \mathrm{~m}$ from the ground.

The velocity field boundary conditions for the ground and the human surface were $\mathbf{u}=0$, without slip (No slip). The right boundary was at $X=17 \mathrm{~m}$ was pressure $p=1 \mathrm{~atm}$. The top boundary condition at $Y=2.5 \mathrm{~m}$ was $\mathbf{u} \cdot \mathbf{n}=0$ with slip. The left boundary at $X=-3 \mathrm{~m}$ was $\mathbf{u}=U_{0} \cdot \mathbf{n}$ with $\mathrm{U}_{0}$ - wind speed.

Different boundary conditions for the convection flow inlet were tested, for example a more realistic linear condition $U_{0}=2 \cdot(Z+2.5 \mathrm{~m}) \cdot U_{0}$, but the influence on the concentration field profile was negligible (less than $10 \%$ in number concentration) if the total mass flow was constant. It could be explained by the position of the aerosol source quite far above the ground $(1.7 \mathrm{~m})$. Therefore, the effect of the ground boundary was small at $1.7 \mathrm{~m}$. A randomization of $U_{0}$ along the $Z$ co-ordinate also gave rather negligible variations in the number concentration field.

The aerosol particles boundary conditions for the ground and the human surface were $C_{X, Z}=0$. The right boundary condition at $X=17 \mathrm{~m}$ was the outflow. The top boundary condition at $\mathrm{Y}=2.5 \mathrm{~m}$ was "No Flux" (Comsol Multiphysics). The left boundary at $X=-3 \mathrm{~m}$ was $C_{X, Z}=0$.

The initial aerosol cloud shape was an ellipsoid with the diameter along the $X$ co-ordinate $-1 \mathrm{~m}$ and the vertical diameter $-0.5 \mathrm{~m}$. The cloud was at $\mathrm{X}=1 \mathrm{~m}, \mathrm{Z}=0.8 \mathrm{~m}$ or $1.7 \mathrm{~m}$ from the ground. The initial aerosol particle concentration inside the cloud was $C_{X, Z}=5 \mathrm{~cm}^{-3}$. In preliminary test runs, it was established that variations in the shape and the volume of the cloud did not influence the results considerably if the larger diameter of the cloud was less than $1.5 \mathrm{~m}$.

Here, simulations were carried out for relatively simple geometries of open spaces. Various wind speeds and turbulent diffusion coefficients were considered. An example of confined environments with and without ventilation facilities was studied in the model too. 


\subsection{Atmospheric Diffusivity and Aerosol Evolution}

Dispersion of aerosol particles in the atmosphere is mainly influenced by the convection, heat transfer and turbulent diffusion. The atmosphere especially near the boundary layer at the size of the human is a non-steady-state non-equilibrium system with extremely complicated structure of boundary conditions. Atmospheric turbulence is intermittent in space and time and comprises eddies ranging from microscale size to meters even near the ground.

The diffusivity of such a patchy turbulence as atmospheric is mainly related to statistical parameters describing the morphology of turbulent events: filling factor, lifetime and height of the patches, etc. (Wilson, 2004). A statistical description of the turbulent characteristics is often employed in order to evaluate the impact of small-scale turbulence on the transport of aerosols. In-situ measurements of atmospheric diffusivity coefficients range from 0.2 to $0.8 \mathrm{~m}^{2} \mathrm{~s}^{-1}$ (Alisse and Sidi, 2000). There are many uncertainties with the atmospheric turbulence, for example greater values and variations in the atmospheric diffusivity from circa 1 to $100 \mathrm{~m}^{2} \mathrm{~s}^{-1}$ have been reported (Kennedy and Shapiro, 1980). In the boundary layer the atmospheric diffusion coefficient is in the range from 0.1 to $160 \mathrm{~m}^{2} \mathrm{~s}^{-1}$ depending on the stability of the atmosphere, the urban geometry and traffic (Hanna et al., 1982). In street canyons the atmospheric diffusion coefficient is likely to be in the range from 0.1 to $10 \mathrm{~m}^{2} \mathrm{~s}^{-1}$, ibid.

To investigate aerosol dispersion over long distance simplifications are required (e.g., see Feng et al., 2020; Vuorinen et al., 2020). Here we employed software where compressible ( $\mathrm{Ma}<0.3)$ Navier-Stokes equations are solved to generate the larger relatively stable eddies, but the smaller short-lived eddies are modelled with integrated atmospheric diffusion approach using the diffusion of diluted species module (COMSOL Multiphysics). The diffusion coefficients are taken from experimental works. This simplification allows modelling of aerosol dispersion on larger scales and it is widely used in studying atmospheric pollution studies from the global scale down to human size scales. This COMSOL Multiphysics approach is similar but not identical to Reynolds averaged Navier-Stokes approach (RANS) in which turbulent motion is not explicitly resolved and its effects on the velocity flow field are modelled using approximate turbulence models. The advantage of the current approach is the computational speed ( 10 min for 3D models) and ability to incorporate the heat transfer, turbulent diffusion and external forces modules. This has been widely used in air quality control and many other applications (COMSOL Multiphysics).

\subsection{Size and Concentration of Droplets Generated by Coughing and Sneezing}

Sneezing and coughing generate clouds of largely liquid aerosol particles in the air mainly in the size range from 1 to $100 \mu \mathrm{m}$ (Zhao et al., 2005; Han et al., 2013).

Particles of different sizes have significantly different dynamic characteristics. Relatively large droplets are deposited within 1 metre due to gravitational settling (Leder and Newman, 2005). Smaller particles can travel longer distances. Gustavo (2012) has detected high concentrations of submicron particles in cough aerosols. The total number concentration of aerosol particles (integrated over all sizes) in some papers is from $10^{3} \mathrm{~cm}^{-3}$ to $2 \cdot 10^{3} \mathrm{~cm}^{-3}$ (Yang et al., 2007). Average size range of the particles was $1-10 \mu \mathrm{m}$, and $50 \%$ of particles have diameter $>10 \mathrm{~mm}$. However, some of small particles may or may not be directly related to coughing but to the background aerosol. The estimated droplet concentrations for coughing ranged from 2.4 to $5.2 \mathrm{~cm}^{-3}$ per cough (Chao et al., 2009). There are many inconsistencies in the literature on particle number and size distribution of aerosol particles generated by speaking, singing, coughing and sneezing. In this paper, the initial concentration of aerosol particles generated by a host considered as an unknown parameter in modelling that does not affect the dispersion of aerosols. If the initial concentration is known, then the modelling results can be readily converted into aerosol particle number concentrations.

The majority of data suggests that size range of particles generated by coughing and sneezing by infected humans is from $1 \mu \mathrm{m}$ to $100 \mu \mathrm{m}$. The particles in the size range from $1 \mu \mathrm{m}$ to $10 \mu \mathrm{m}$ are part of $\mathrm{PM}_{10}$ characteristic and well researched, for example it is known that they stay airborne for some time (minutes to hours) and travel long distances (more than $10 \mathrm{~s}$ of meters). Dispersion of larger particles $10 \mu \mathrm{m}$ to $100 \mu \mathrm{m}$ is less understood. The larger particles have a greater viral load than the small particles (on average 1000 times greater), therefore, a contribution of larger particles to the COVID-19 aerosol transmission route should be better understood. Here we investigate dispersion of aerosol particles of the size range from $10 \mu \mathrm{m}$ to $100 \mu \mathrm{m}$. 


\subsection{Viral Load}

There are many uncertainties with quantification of the viral load. The median viral load in posterior oropharyngeal saliva or other respiratory specimens is $5.2 \mathrm{log}$ copies per $\mathrm{ml}$ and maximal virus loading is found circa $10^{8}$ copies $\mathrm{mL}^{-1}$ (To et al., 2020). The viral loads in throat swab and sputum samples peaked at around 5-6 days after symptom onset, ranging from around $10^{3}$ to $7.11 \cdot 10^{8}$ copies $\mathrm{mL}^{-1}$ according to Health Information and Quality Authority (2020). The viral loads, as identified by values of RT-PCR assay, have been reported to be highest soon after the onset of symptoms reaching up to $10^{8}$ copies $\mathrm{mL}^{-1}$ (Zou et al., 2020). There is no direct evidence on the viral load in aerosol particles generated by an infected person. The data obtained from swabs are used here as a proxy to evaluate the number of virus copies in aerosol particles. In the absence of direct measurements, the assumption of equal viral loads in the posterior oropharyngeal saliva and in aerosol particles is accepted here.

Here we model atmospheric transfer at various conditions including atmospheric diffusion coefficient $\left(0.1 \mathrm{~m}^{2} \mathrm{~s}^{-1}-10 \mathrm{~m}^{2} \mathrm{~s}^{-1}\right)$, size of aerosol particles/droplets $(10 \mu \mathrm{m}-100 \mu \mathrm{m})$ and concentration is modelled in dimensionless units that can be easily adjusted to any starting value. The range of parameters is essential to limit uncertainties with assumptions on parameters to ensure that using variations in parameters would not change the conclusions dramatically.

\section{RESULTS AND DISCUSSIONS}

Two types of aerosol source have been modelled: a steady-state source and time-dependent source. The first one is a simplification of a constant aerosol generation process such as during talking or singing. The latter is related to a single coughing or sneezing act, generating a cloud that evolves and moves with time.

\subsection{Steady-state Aerosol Source X-Z Plane}

It was found that aerosol particles were carried out with the convection flow and spread from the source along the Z-coordinate, Fig. 1. The aerosol particle concentration field forms a narrow plume from the source directed slightly to the ground. If we assume that the initial concentration of particles in the cloud is $C_{0}=5 \mathrm{~cm}^{-3}$ then the concentration shown with a red contour line $(C, X Y$ $=0.3 \cdot C_{0}$ ) reaches almost $6 \mathrm{~m}$ distant from the source for wind speed $1 \mathrm{~m} \mathrm{~s}^{-1}$, Fig. $1(\mathrm{~A})$. The concentration shown with the yellow contour line $\left(C_{X, Y}=0.2 \cdot C_{0}\right)$ covers over 10-meter distance from the source of the aerosol particles. Interestingly the green contour line $\left(C_{X, Y}=0.1 \cdot C_{0}\right)$ is spread beyond $X=12$ meters. The concentration field is asymmetric due to influence of the ground boundary conditions. The upwind area is completely clean from aerosol particles emitted from the source. Modelling demonstrates a strong influence of convection on the spread of aerosol particles along the $\mathrm{X}$-axis, but diffusivity is responsible for dispersion of particles along the $\mathrm{Y}$-axis and Z-axis.

On a quiet day, the average air wind speed at the height of 1.5 to 2 meters above the ground is from $0.3 \mathrm{~m} \mathrm{~s}^{-1}$ to $1 \mathrm{~m} \mathrm{~s}^{-1}$. On a moderate day, with a higher wind speed, for example $3 \mathrm{~m} \mathrm{~s}^{-1}$, red and yellow contour lines are shrunk, but the green line extends beyond the model border, $\mathrm{X}$ $=17 \mathrm{~m}$, Fig. 1(B). This shows that the faster movement of the aerosol decreases the concentration of particles due to a greater dilution of the aerosol. This effect is well known in air pollution research when higher wind speed episodes are associated with lower concentrations of aerosol particles. This decreases the area of the plume and therefore, chances that the general public will be exposed to the virus laden aerosol particles. Therefore, in a windy day the viral infection transfer rate should be lower than in a quiet day.

The atmospheric diffusivity also influences the aerosol dispersion. An increase in the diffusion coefficient from Dif $=0.01 \mathrm{~m}^{2} \mathrm{~s}^{-1}$ (Fig. 1(A)) to Dif $=0.1 \mathrm{~m}^{2} \mathrm{~s}^{-1}$ (Fig. 1(C)) increases the vertical spread of the contour plots but shortens them in the X-axis. A spectacular manifestation of the effects of diffusion is shown in Fig. 1(C) with magenta streamlines obtained with Dif $=0$. This is the case of an unrealistic steady-state laminar flow without turbulent diffusion when an aerosol cloud travels the distance determined by the gravitational force and the wind speed.

The model built enables complicated geometries to be studied. If a car is placed in an open space, for example a parking area near a supermarket then the air flow can be disturbed by the 
$\mathrm{m}$

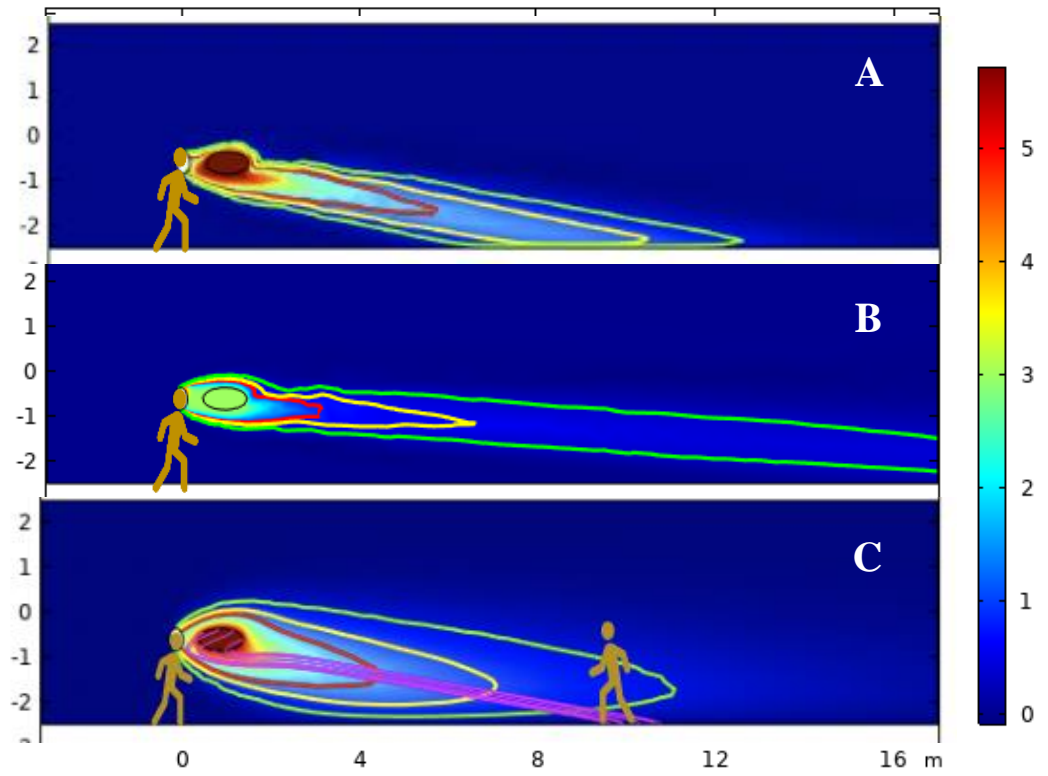

Fig. 1. Number concentration of aerosol particles field in $\mathrm{cm}^{-3}$ modelled for an aerosol open space geometry with a single aerosol source (brown figure looking to the right). Diameter of aerosol particles $100 \mu \mathrm{m} ; \mathrm{RH}=90 \% . \mathrm{T}=20^{\circ} \mathrm{C}$. (A) wind speed $-1 \mathrm{~m} \mathrm{~s}^{-1}$ and the turbulent diffusion coefficient Dif $=0.01 \mathrm{~m}^{2} \mathrm{~s}^{-1}$; (B) wind speed $-3 \mathrm{~m} \mathrm{~s}^{-1}$ and the turbulent diffusion coefficient Dif = $0.01 \mathrm{~m}^{2} \mathrm{~s}^{-1}$; (C) wind speed $-1 \mathrm{~m} \mathrm{~s}^{-1}$ and the turbulent diffusion coefficient Dif $=0.1 \mathrm{~m}^{2} \mathrm{~s}^{-1}$. Magenta streamlines in Fig. 1(C) show an unrealistic case of aerosol particle trajectories without the atmospheric diffusion (Dif $=0$ ).

car and change the aerosol concentration field. The flow of aerosol particles is carried over a car near the source and extended zone of high concentration, Fig. 2.

In this case a person at $X=10 \mathrm{~m}$ is in the middle of the green contour line and exposed to aerosol concentration in the range $0.1 \cdot C_{0}<C_{X, Z}<0.2 \cdot C_{0}$. Without car a person in the same place would be exposed the aerosol concentration $C_{X, z}<0.1 \cdot C_{0}$, Fig. $1(C)$. There is also a large stagnation zone behind the car where several large eddies are formed between $X=7 \mathrm{~m}$ and $17 \mathrm{~m}$, Fig. 3 . It should be noticed that the largest eddy at $\sim 12 \mathrm{~m}$ causes the backwind trajectories of the magenta streamlines. Similar effects were observed in models with other obstacles: trees, shrubs, people, etc. The considered cases were modelled in a humid air $\mathrm{Rh}=90 \%$ with aerosol particles of $100 \mu \mathrm{m}$ diameter. It is a worst-case scenario when evaporation is negligible, and the terminal velocity of particles is largest. Therefore, in all other cases travel distances of aerosol particles should be greater. Thus, in open spaces various obstacles to the wind may increase the spread of viral infections.

The influence of heat transfer on the air dynamic and the aerosol particle concentration was investigated in cases when a car shown in Fig. 2 has an elevated boundary temperature as after been driven. In the model runs the surface of the car boundary vas varied from $30^{\circ} \mathrm{C}$ to $40^{\circ} \mathrm{C}$. the influence of the elevated temperature was found to be negligible. Thus, this type of heat transfer was not essential for aerosol cloud dispersion. However, for other geometries and conditions effects of heat transfer can be greater.

\subsection{Steady-state Aerosol Source X-Y Plane}

The aerosol cloud dispersion in the horizontal $X-Y$ plane was calculated at $Z=1.7 \mathrm{~m}$ in the same way as it was done for modelling aerosol travel in the vertical plane $(X-Z)$. In the model, a concentration field of smaller $10 \mu \mathrm{m}$ diameter particles have been calculated in $X-Y$ space $(-3 \mathrm{~m}$ $<X<17 \mathrm{~m} ;-5 \mathrm{~m}<\mathrm{Y}<5 \mathrm{~m}$ ). The aerosol source (the mouth of the host head) was at $X=0, Y=0$ at $1.7 \mathrm{~m}$ from the ground.

The velocity field boundary conditions for boundaries at $Y=5 m$ and at $Y=-5 m$ were allowing slip. The rest of boundary conditions were the same as in the $\mathrm{X}-\mathrm{Z}$ modelling. 


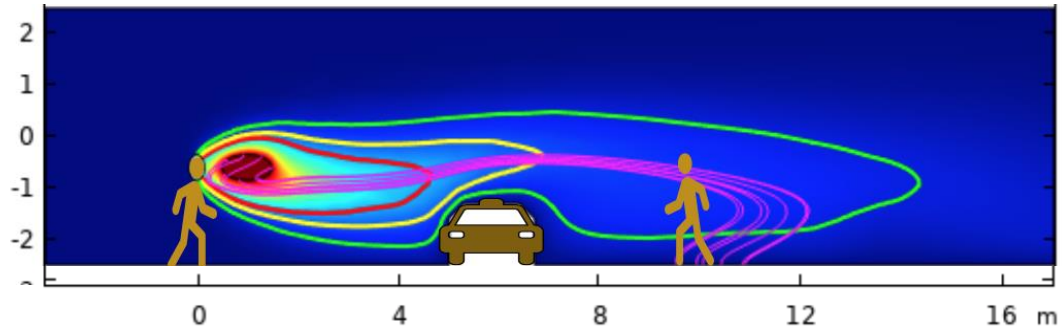

Fig. 2. Number concentration of aerosol particles field in $\mathrm{cm}^{-3}$ modelled for an aerosol open space geometry with a single aerosol source (brown figure looking to the right). Diameter of aerosol particles $100 \mu \mathrm{m} ; \mathrm{RH}=90 \% . \mathrm{T}=20^{\circ} \mathrm{C}$. Wind speed $-1 \mathrm{~m} \mathrm{~s}^{-1}$ and the turbulent diffusion coefficient Dif $=0.01 \mathrm{~m}^{2} \mathrm{~s}^{-1}$. A car is placed at $\mathrm{X}=6 \mathrm{~m}$. The concentration color legend is the same as in Fig. 1 .

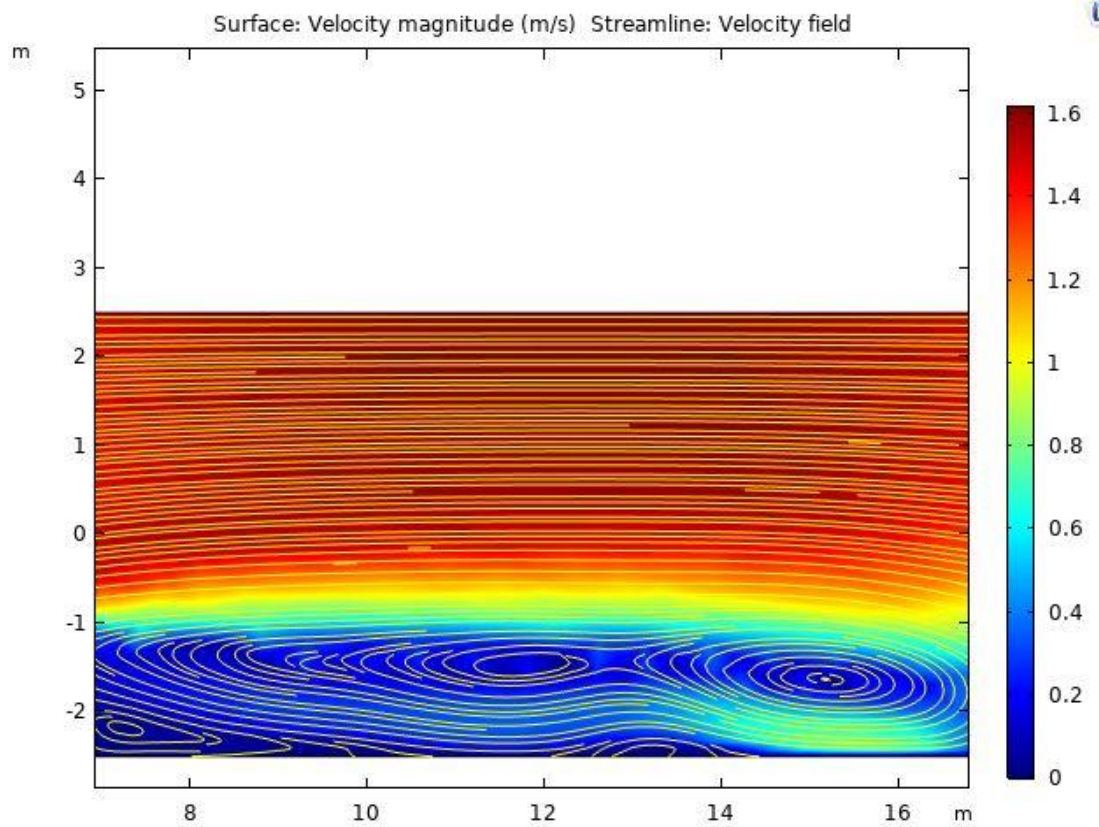

Fig. 3. A magnified air velocity field for of aerosol particles of $100 \mu \mathrm{m} ; \mathrm{RH}=90 \%$. $\mathrm{T}=20^{\circ} \mathrm{C}$. Wind speed $-1 \mathrm{~m} \mathrm{~s}^{-1}$ and the turbulent diffusion coefficient Dif $=0.01 \mathrm{~m}^{2} \mathrm{~s}^{-1}$. A car is placed at $\mathrm{X}=6 \mathrm{~m}$ (not in the frame). Symbols of humans have been removed to make eddies clear visible. The velocity color legend is in $\mathrm{m} \mathrm{s}^{-1}$.

It was found that aerosol particles were carried out with the convection flow and spread from the source in all directions. An open space geometry modelled with wind speed $0.3 \mathrm{~m} \mathrm{~s}^{-1}(0.66 \mathrm{mph})$ shows that small particles travel considerable distances, greater than 15 meters, Fig. 4.

An aerosol particle concentration field forms a plume from the source directed downwind. The concentration field is highly asymmetric. The upwind area is completely clean from aeroso particles emitted from the source. Modelling demonstrates a strong influence of convection on the spread of aerosol particles along the X-axis and diffusivity - along the Y-axis.

An increase in the wind speed from $0.3 \mathrm{~m} \mathrm{~s}^{-1}$ to $1 \mathrm{~m} \mathrm{~s}^{-1}$ leads to decrease of the length of each contour plot. For example, the yellow contour line covers less than 9-meter length, Fig. 5 where in Fig. 4 it is 15 meters. This is explained by a greater dilution of the aerosol at higher speed of wind. This supports findings in the modelling in $X-Z$ plane that an increase in the wind speed reduces exposure to aerosol particles.

\subsection{Time-dependent Modelling of Evolution of an Aerosol Cloud in an Open Space}

A supermarket car park $(10 \mathrm{~m} \times 20 \mathrm{~m})$ with a moderate wind speed in a dry weather is 


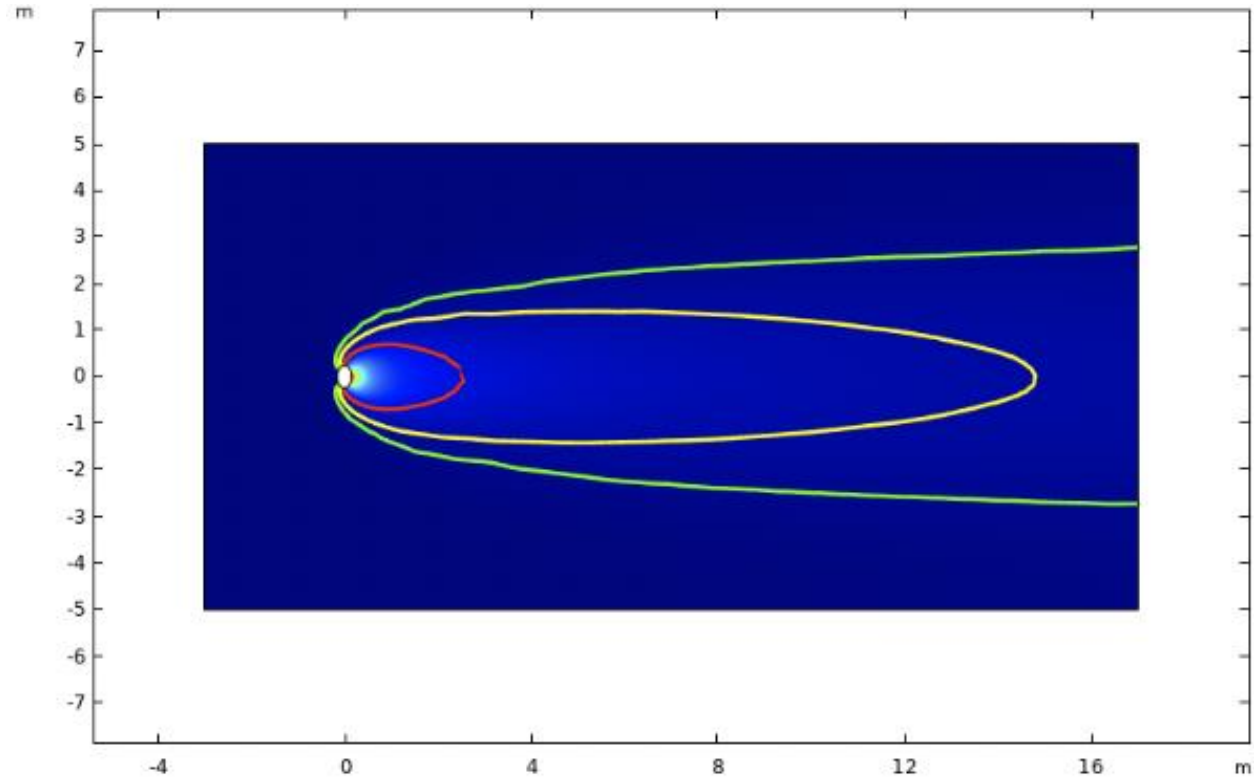

Fig. 4. Contour plot for the concentration field of aerosol particles ( $10 \mu \mathrm{m}$ diameter) from a single source in $X-Y$ plane $20 \mathrm{~m} \times 10 \mathrm{~m}$. Wind speed $-0.3 \mathrm{~m} \mathrm{~s}^{-1}(0.66 \mathrm{mph})$, atmospheric diffusivity $0.05 \mathrm{~m}^{2} \mathrm{~s}^{-1}$. Contour lines show the concentration of aerosol particles: $\left(C, X Y=0.3 \cdot C_{0}\right)-$ red; $(C, X Y$ $\left.=0.2 \cdot C_{0}\right)$-yellow; $\left(C_{, X Y}=0.1 \cdot C_{0}\right)-$ green. $\mathrm{RH}=50 \% . \mathrm{T}=20^{\circ} \mathrm{C}$. The initial concentration of particles in the cloud is $C_{0}=5 \mathrm{~cm}^{-3}$.

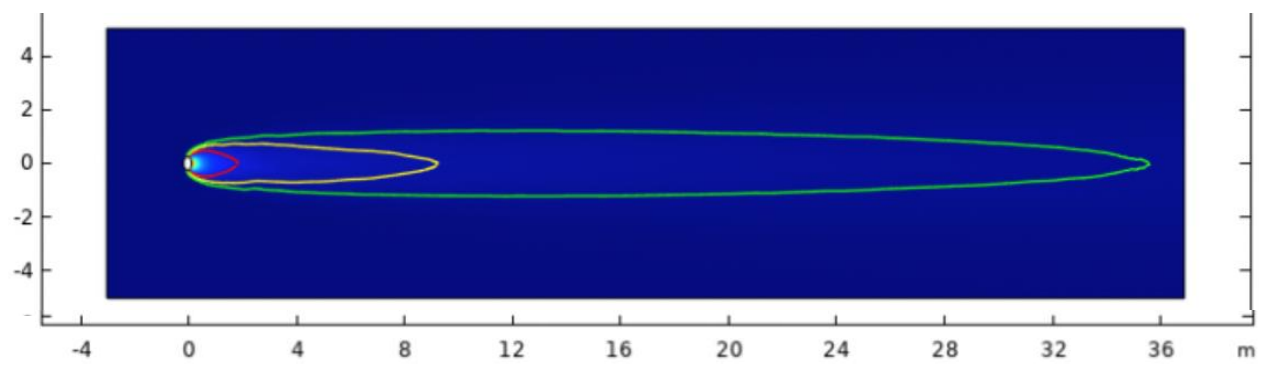

Fig. 5. Contour plot for the concentration field of aerosol particles from a single source in the area of $40 \mathrm{~m} \times 10 \mathrm{~m}$. Velocity of air $-1 \mathrm{~m} \mathrm{~s}^{-1}(2.2 \mathrm{mph})$, atmospheric diffusivity $-0.05 \mathrm{~m}^{2} \mathrm{~s}^{-1}$. Contour lines show the concentration of aerosol particles: $\left(C, X Y=0.3 \cdot C_{0}\right)-$ red; $\left(C_{, X Y}=0.2 \cdot C_{0}\right)-$ yellow; $\left(C, X Y=0.1 \cdot C_{0}\right)-$ green. With $\mathrm{RH}=50 \%$ and $\mathrm{T}=20^{\circ} \mathrm{C}$. The initial concentration of particles in the cloud is $C_{0}=5 \mathrm{~cm}^{-3}$. An extended version of the geometry is shown in Fig. 4 .

considered. A single infected person generates an aerosol cloud (by a single cough) containing small $(1 \mu \mathrm{m}<D p<10 \mu \mathrm{m})$ and larger $(100 \mu \mathrm{m}>D p>10 \mu \mathrm{m})$ aerosol particles; where $D p$ is the aerodynamic diameter of a particle, Baron and Willeke (2001). In typical air $\left(\mathrm{RH}=50 \%, \mathrm{~T}=20^{\circ} \mathrm{C}\right.$ ) the larger aerosol particles quickly release the water vapor that reduces the terminal velocity considerably (Vuorinen et al., 2020). The convection is also influenced by buoyancy, movement of people, machines and animals. In this modelling, all the driving forces of convection except for the wind velocity were integrated into an atmospheric diffusion coefficient.

The initial size of the aerosol cloud generated by a single cough was assumed to be $0.5 \mathrm{~m} \times 1 \mathrm{~m}$ ellipse with concentration of particles $C_{0}=5 \mathrm{~cm}^{-3}$. After the first 6 seconds the cloud has grown up to 6 meters, see aerosol particles concentration contour line $C_{X Y}=0.1 \cdot C_{0}$ (green line) in Fig. 6 . Then the cloud moved with the wind further along the $X$-axis and become wider in the $X-Y$ plane, see a supplementary video. At the same time the particle concentration in the cloud is decreasing due to dispersion by atmospheric diffusion. The black contour line disappeared first and then the red line disappeared also. Therefore, non-steady-state modelling confirms that aerosol particles generated by a cough can travel considerable distances from the source in excess of 10 meters. 


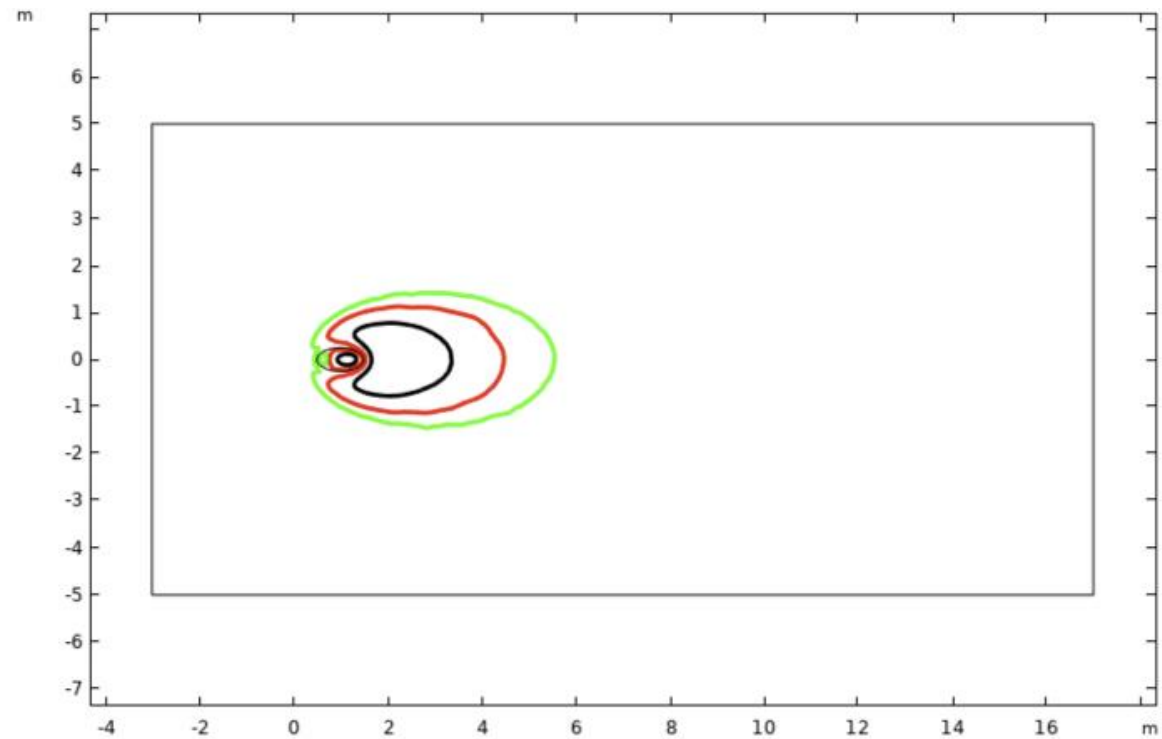

Fig. 6. An XY cross-section of number concentration field of aerosol particles at the beginning of the aerosol cloud evolution, time $-6 \mathrm{~s}$. Wind speed $0.3 \mathrm{~m} \mathrm{~s}^{-1} ; \mathrm{T}=20^{\circ} \mathrm{C} ; \mathrm{RH}=50 \%$; diffusivity $D f=$ $0.03 \mathrm{~m}^{2} \mathrm{~s}^{-1}$. The contour lines are: $\left(C_{, X Y}=0.3 \cdot C_{0}\right)-$ red; $\left(C_{, X Y}=0.2 \cdot C_{0}\right)-$ yellow; $\left(C_{X Y}=0.1 \cdot C_{0}\right)-$ green. Other conditions as in previous steady-state model.

\subsection{D Modelling in Confined Spaces}

The modelling in open spaces was adapted to confined spaces. For this the wind speed was replaced by convection driven by buoyancy (e.g., caused by heating radiators and electronic devices) and ventilation. These create a complex non-uniform 3D velocity field. In modelling, integrated diffusion coefficients were employed as in the modelling of the open spaces.

The rectangular geometry with a $4 \mathrm{~m} \times 6 \mathrm{~m}$ footprint and $3 \mathrm{~m}$ height with an inlet and an outlet ventilation and with 3 beds was modelled, Fig. 7. The ventilation flow rate was $Q=0.1 \mathrm{~m}^{3} \mathrm{~s}^{-1}$ and the volume exchange is 5 times per hour $\left(V=72 \mathrm{~m}^{3}\right)$. Boundary conditions were as described in the $2 \mathrm{D}$ sections.

It was found that from the inlet the ventilation flow was directed to the floor where it changed direction and moved almost horizontally, see the $Y-Z$ plane at $X=0.5 \mathrm{~m}$ in Fig. 8. The effects of buoyancy (driven by differences in temperature) on the convection flow were found to be greater in the confined space than in open spaces. If a radiator in a confined space (not shown in Fig. 7) was at $\mathrm{T}=50^{\circ} \mathrm{C}$ or $30^{\circ} \mathrm{C}$ higher than the wall temperature, the heat induced convection velocity flow was the same order of magnitude than the ventilation flow velocity. Therefore, in confined spaces heat transfer has to be taken into account.

A possible scenario of contaminated ventilation with the initial aerosol concentration $\mathrm{C}_{0}=$ $1 \mathrm{~cm}^{-3}$ was modelled. Modelling shows that in the confined space, aerosol particles occupy a considerable part of the room volume. If a person is in the bed at $Y=1 \mathrm{~m}$ he/she is exposed to $C, X Y>0.2 \cdot C_{0}$ that is greater than the exposure level for a person in the bed at $Y=5 \mathrm{~m}$ where $C, X Y$ $<0.1 \cdot C_{0 .}$, Fig. 9.

The difference between an open space and a confined space scenario is the volume where the aerosol is dispersed and the number of aerosol emission acts. 3D modelling does not contradict to a possibility that viral infections can be transformed via ventilation in confined spaces. However, there are very limited data available on direct measurements of viral presence in ventilation facilities. Airborne viral infection transmission via ventilation is an important issue for multistore buildings including hospitals and care homes and should be investigated along with other transmission routes.

\subsection{Accumulated Dose of Viral Load and Exposure to Large Aerosol Particles/Droplets}

This modelling confirms a potential possibility of the aerosol route for transmission of COVID-19 


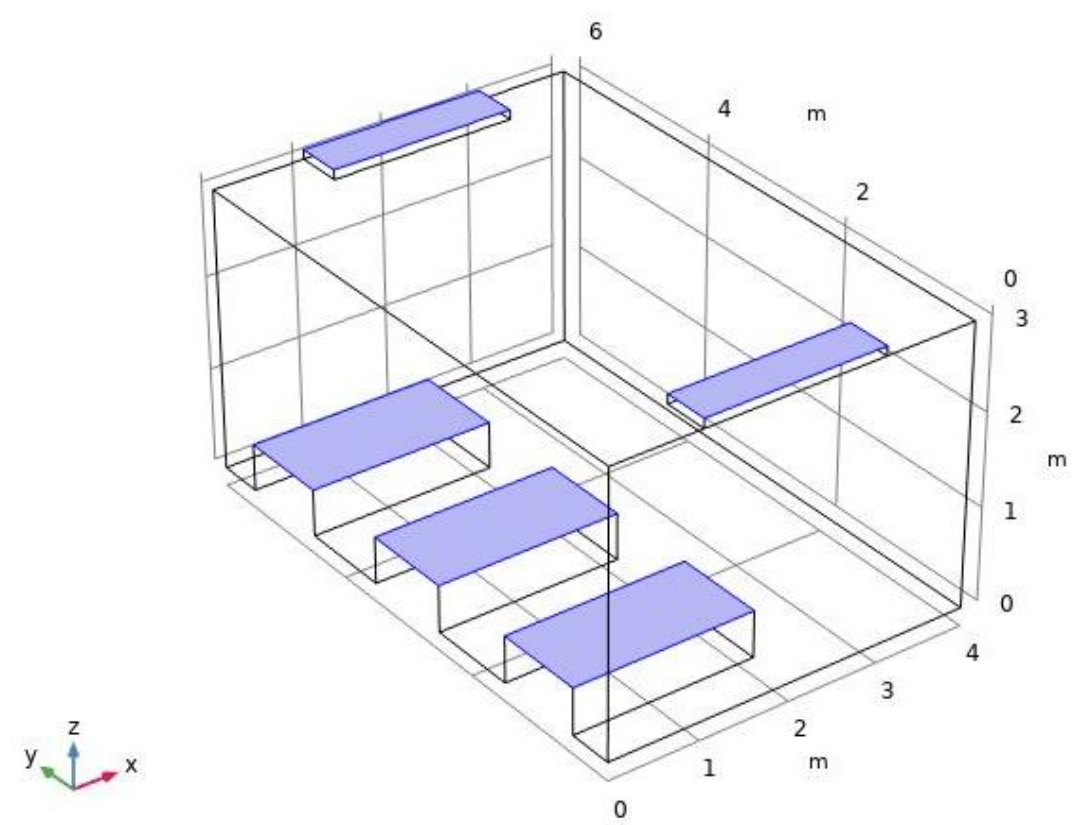

Fig. 7. Geometry for 3D modelling of aerosol dispersion. The model includes three blue top rectangular beds at the ground level, a ventilation inlet at $\{1 \mathrm{~m}<\mathrm{X}<3 \mathrm{~m} ; 0<\mathrm{Y}<0.4 \mathrm{~m} ; \mathrm{Z}=3.1 \mathrm{~m}\}$ and a ventilation outlet at $\{1 \mathrm{~m}<\mathrm{X}<3 \mathrm{~m} ; 5.6 \mathrm{~m}<\mathrm{Y}<6 \mathrm{~m} ; \mathrm{Z}=3.1 \mathrm{~m}\}$.

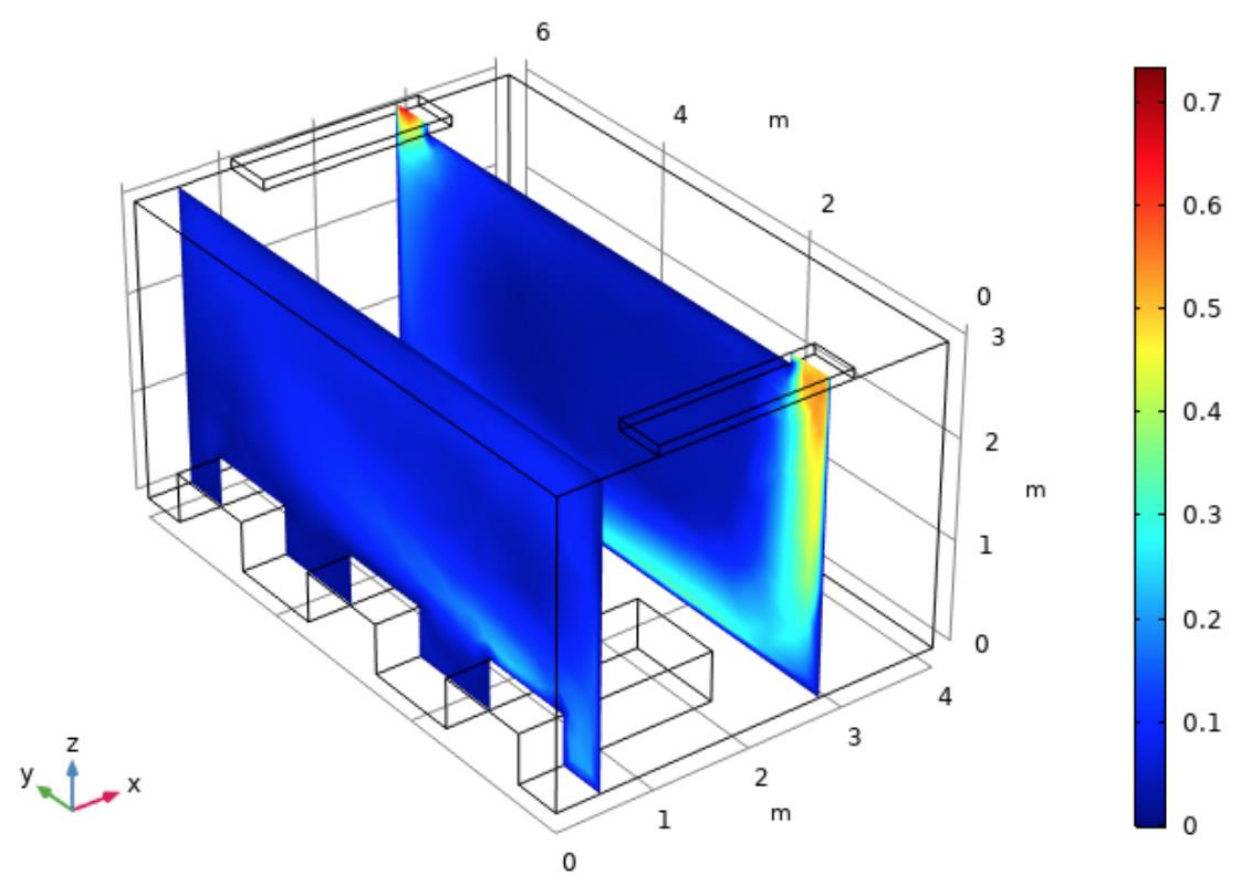

Fig. 8. Velocity field for the ventilation velocity vairin $=0.1 \mathrm{~m} \mathrm{~s}^{-1}$; Difcov $=0.1 \mathrm{~m}^{2} \mathrm{~s}^{-1} ; \mathrm{T}=20^{\circ} \mathrm{C} ; \mathrm{RH}$ $=50 \%$; The color-coded legend shows velocity in $\mathrm{m} \mathrm{s}^{-1}$.

infection. In this section we are using the modelling results and the literature data to investigate exposure - dose relationships relevant to viral load that can be transferred from a host to a healthy individual. To evaluate transfer of a viral infection, first an aerosol particle concentration field $C_{X, Y, Z, t}$ was calculated as described above and then the ICRP lung deposition model was applied to estimate the number of aerosol particles deposited in the respiratory tract (Hinds, 1999; Gorbunov et al., 2009), Fig. 10. 


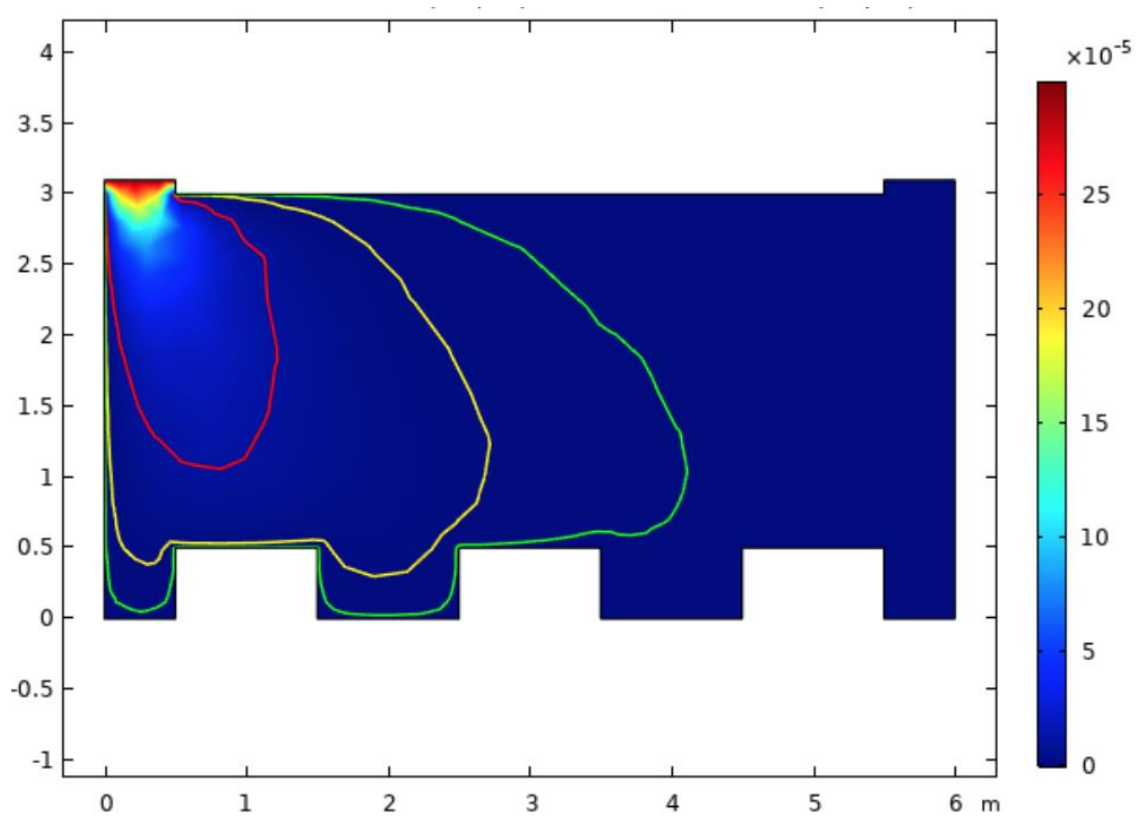

Fig. 9. Aerosol particle concentration field in a $Y-Z$ plane at $X=2 \mathrm{~m}$. The conditions are the same as in Fig. 8. Contour lines are: $\left(C, X Y=0.3 \cdot C_{0}\right)-$ red; $\left(C, X Y=0.2 \cdot C_{0}\right)-$ yellow; $\left(C, X Y=0.1 \cdot C_{0}\right)-$ green. $\mathrm{C}_{0}=1 \mathrm{~cm}^{-3}$.

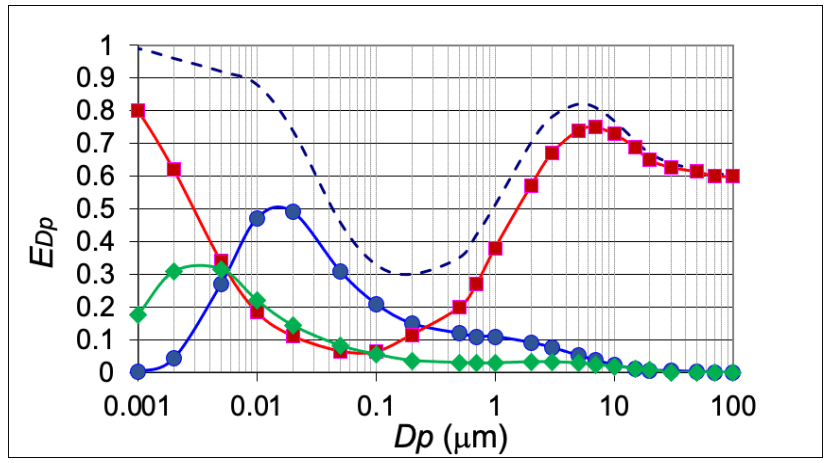

Fig. 10. Aerosol particle deposition efficiency curves $\left(E_{D p}\right)$ vs. diameter of aerosol particles. The total deposition in the respiratory system shown with the dashed black curve and regional depositions are shown with colored lines: the upper respiratory tract (red line), tracheobronchial region (green line) and alveolar region (blue line).

The total number of particles deposited in the respiratory system of a person who is at a point $\{X, Y, Z, t\}$ after a single cubic centimetre of the aerosol breathed in $\left(N_{p d}\right)$ can be found from:

$N_{p d}=\int_{D p=1 \mu}^{D p=100 \mu} C_{X, Y, Z, t, D p} \cdot E_{D p} d D p$

Here $E_{D p}$ is the deposition efficiency of aerosol particles in the respiratory system as function of the particle size, Fig. 10. The aerosol particle number size distribution has been included in expression (1) and indicated as a symbol $D p$ in $C_{X, Y, Z, t, D p}$ (Gorbunov et al., 2013). So expression (1) $C_{X, Y, Z, t, D p}$ is a 5-dimensional function of space, time and particle size.

According to the ICRP deposition efficiency curve, the particles relevant to COVID-19 transmission $(1 \mu \mathrm{m}<D p<100 \mu \mathrm{m})$ are captured mainly by the upper respiratory tract. Therefore, the face masks for COVID-19 should be designed to filter out particles in the range from $1 \mu \mathrm{m}$ to $100 \mu \mathrm{m}$ preferably with maximal efficiency at the $E_{D p}$ maximum $-5 \mu \mathrm{m}$. The current face mask 
industry standard does not include testing in this size range (Lee et al., 2016). The initial size distribution of droplets was taken from Yang et al. (2007).

First, to calculate the viral load, one has to find the total volume of aerosol particles in $1 \mathrm{~cm}^{3}$ of air that deposited in the respiratory tract $\left(V_{p d}\right)$.

$V_{p d}=\frac{4}{3} \pi \int_{D p=100 \mu}^{D p=1 \mu} C_{X, Y, Z, t, D p} E_{D p} \cdot\left(\frac{D p}{2}\right)^{3} d D p$

The accumulated dose of the viral load $\left(A D_{p d}\right)$ is the total number of virus copies deposited in the respiratory tract after number of breathing cycles $n$ and the volume of a single breath $\left(V_{1}\right)$. The viral load of the posterior oropharyngeal saliva is $b$. Evaporation of water from aerosol particles/droplets results in increasing the viral load (Baron and Willeke, 2001). This effect is accounted for by the humidity factor $H_{f}$ that ranges from 1 for a humid air to 300 for the dry air (Vuorinen et al., 2020).

It should be noted that $n$ may or may not be constant. It is influenced by the physical activity, fitness level, age and gender. The average breath rate is $\sim 5$ cycles per minute.

$A D_{p d}=V_{p d} \cdot V_{1} \cdot n \cdot b \cdot H_{f}$

The number of breath cycles and the concentration of the aerosol particles define the deposition dose of a person that is exposed to an aerosol. The humidity in modelling was $\mathrm{RH}=$ $50 \%$ (low humidity) and $\mathrm{RH}=90 \%$ that is close to humidity of the exhaled air $\mathrm{Rh}=87 \%$.

Let us consider a healthy person standing at point $\{12 \mathrm{~m}, 0,1.7, t\}$ as in Fig. 4 where he/she is exposed to aerosol particles $D p=20 \mathrm{~mm}$ with $C_{X, Y, Z, t, D p}=1 \mathrm{~cm}^{-3}, n=10$ and $b=10^{5}$ virus copies cm $\mathrm{cm}^{-3}$. The viral dose received by the person was found to be 20 copies of viruses in a humid air and considerably more in dryer air (circa 100 copies depending on the $\mathrm{RH}$ ).

The critical viral load dose for COVID-19 is not well studied and further research is required. However, there is a demand to quantify the risk of the infection transfer via the aerosol route. The expressions ( 2 ) and ( 3 ) can be used to quantify the dose and potentially to be employed as a measure of the risk associated with exposure to airborne viruses like SARS-CoV-2.

The modelling developed here is a simplified approach where all statistical variabilities of the aerosol evolution in real environments are accounted for by the integrated turbulent diffusion coefficient superimposed on the laminar flow solution. There is a question of uncertainties associated with this approach. However, it is unlikely that these uncertainties affect the main conclusions of the current work. Under the circumstances a fast software (1-10 min computation time with PC) widely used and verified in a different field can be rather useful in evaluation of the airborne virus transfer and evaluating the risk associated with exposure to airborne viruses.

\subsection{Limitations and Assumptions in Modelling}

The general set of Navier-Stokes equations governs the motion of compressible Newtonian fluids. Running simulations using the original NS equations is often beyond the computational power of most of today's computers and supercomputers (Comsol Multiphysics software). Instead, a Reynolds-Averaged Navier-Stokes formulation of the Navier-Stokes equations, which averages the velocity and pressure fields in time is used. This assumption has been validated and widely accepted in air pollution modelling.

It is assumed here that the aerosol particle - air boundary can be treated according to Cunningham by introducing a slip correction factor (Baron and Willeke, 2001). This limitation is common in the aerosol science and very well validated. In addition, the density of aerosol particles/droplets was assumed to be $1.0 \mathrm{~g} \mathrm{cc}^{-1}$. It is a limitation, but it is unlikely that a small density change may noticeably affect the length of particle dispersion in the air.

Another assumption is the isotropic diffusion of the atmosphere along the model vertical dimension (from the ground level up to $5 \mathrm{~m}$ ). The main reason for this is lack of reliable data on anisotropic diffusivity near the ground in complex environments and large uncertainties with experimental results. To minimize effects of these uncertainties modelling were carried out with a range of diffusion coefficients. 


\subsection{Possible Experimental Verification of the $\mathbf{3 0 ~} \mathrm{m}$ Travel of Aerosol Particles \\ (10 $\mu \mathrm{m}$ to $100 \mu \mathrm{m}$ Diameter)}

SARS-CoV-2 viruses have been observed in the air, see for example Liu et al. (2020). The modelling predicts measurable concentrations at $30 \mathrm{~m}$ distance from the source. However, concentration of particles/droplets is small. From theoretical point of view, the particles can be studied employing a cascade impactor, e.g., Gorbunov et al. (2009) to fractionate particles, optical microscopy to count them and PCR technique for identification of viruses. However, in practice it might be challenging to synchronize emission act, wind direction and sampling device.

Alternatively, verification of modelling predictions could be done with a deactivated virus placed in a matrix of relevant body fluid, for example the lung fluid or saliva. This formulation can be aerosolized using either spinning disc aerosol generator, vibration orifice generator, or similar (Baron and Willeke, 2001). The generator can be positioned stationary and run in preferable stable atmospheric conditions of moderate turbulence. In this case an issue of synchronization is addressed. The concentration of aerosol particles/droplets generated can also be considerably greater than concentration in a single act of sneezing. This experiment will be a steady-state experiment. The aerosol particles can be collected with either a cascade impactor or an aerosol filter.

\section{CONCLUSIONS}

- The results obtained confirmed that aerosol particles from a host can travel distances considerably longer than the currently recommended $2 \mathrm{~m}$ safe distance. Aerosol particles of diameters from $10 \mu \mathrm{m}$ to $100 \mu \mathrm{m}$ that potentially can carry SARS-CoV-2 (COVID-19) viruses travel over $30 \mathrm{~m}$ at some atmospheric conditions.

- Modelling the evolution of aerosol clouds generated by coughing and sneezing reveals that in realistic weather scenarios up to 200 virus copies can be deposited in the upper respiratory tract of a healthy individual.

- A metric based on aerosol particle size distribution and ICRP lung deposition model is suggested.

- The modelling demonstrates how the aerosol particle dispersion is influenced by the weather and geometry of the space.

\section{ACKNOWLEDGMENTS}

The author wishes to thank Dr. J. Rowles in this study for help with preparation of the manuscript.

\section{DISCLAIMER}

Reference to any companies or specific commercial products does not constitute or imply any endorsement.

\section{SUPPLEMENTARY MATERIAL}

Supplementary data associated with this article can be found in the online version at https://doi.org/10.4209/aaqr.200468

\section{REFERENCES}

Alisse, J.R., Sidi, C. (2000). Experimental probability density functions of small-scale fluctuations in the stably stratified atmosphere. J. Fluid. Mech. 402, 137-162. https://doi.org/10.1017/S0 022112099006813

Baron, P.A., Willeke, K. (2001). Aerosol measurement: Principles, techniques and applications. 
John Wiley \& Sons, New York.

Bourouiba, L. (2020). Turbulent gas clouds and respiratory pathogen emissions: Potential implications for reducing transmission of covid-19. JAMA 323, 1837-1838. https://doi.org/10. 1001/jama.2020.4756

Carvalho, T.C., Peters, J.I., Williams, R.O. (2011). Influence of particle size on regional lung deposition - What evidence is there? Int. J. Pharm. 406, 1-10. https://doi.org/10.1016/j.ijphar m.2010.12.040

CDC (2020). CDC Recommends Public Wear Face Masks. https://www.cdc.gov/

Chao, C.Y.H., Wan, M.P., Morawska, L., Johnson, G.R., Ristovski, Z.D., Hargreaves, M., Mengersen, K., Corbett, S., Li, Y., Xie, X., Katoshevski, D. (2009). Characterization of expiration air jets and droplet size distributions immediately at the mouth opening. J. Aerosol Sci. 40, 122-133. https://doi.org/10.1016/j.jaerosci.2008.10.003

Comsol (2020) Multiphysics software. https://uk.comsol.com/multiphysics

Domingo, J.L., Marques, M., Rovira, J. (2020). Influence of airborne transmission of SARS-CoV-2 on COVID-19 pandemic. A review. Environ. Res. 188, 109861. https://doi.org/10.1016/j.envre s.2020.109861

Eissenberg, T., Shihadeh, S.S., Shihadeh, A.L. (2020). Treat COVID-19 as though it is airborne: it may Be. AANA J. 88, 29-30.

Feng, Y., Marchal, T., Sperry, T., Yi, H. (2020). Influence of wind and relative humidity on the social distancing effectiveness to prevent COVID-19 airborne transmission: A numerical study. J. Aerosol Sci. 147, 105585. https://doi.org/10.1016/j.jaerosci.2020.105585

Gorbunov, B., Priest, N.D., Muir, R.B., Jackson, P.R., Gnewuch, H. (2009). A novel size-selective airborne particle size fractionating instrument for health risk evaluation. Ann. Occup. Hyg. 53, 225-237. https://doi.org/10.1007/978-1-4020-9491-0_17

Gorbunov, B., Muir, R., Jackson, P., Priest, N.D. (2013). Evaluation of the airborne particles fraction responsible for adverse health effects. Aerosol Air Qual. Res. 13, 1678-1692. https://doi.org/10.4209/aaqr.2013.02.0039

Haines, A., Scheelbeek, P., Abbasi, K. (2020). The health case for urgent action on climate change. BMJ 368, m1103. https://doi.org/10.1136/bmj.m1103

Han, Z.Y., Weng, W.G., Huang, Q.Y. (2013). Characterizations of particle size distribution of the droplets exhaled by sneeze. J. R. Soc. Interface 10, 20130560. https://doi.org/10.1098/rsif.201 3.0560

Hanna, S.R., Briggs, G.A., Hosker, R.P. Jr. (1982) Handbook on atmospheric diffusion, Smith, J.S. (Ed.), US Department of Energy. p. 103.

Health Information and Quality Authority (2020). Evidence summary for SARS-CoV-2 viral load and infectivity over the course of an infection. 9 June 2020, Health Information and Quality Authority. Report. https://www.hiqa.ie/sites/default/files/2020-06/Evidence-Summary_SARSCoV-2-duration-of-infectivity.pdf

Hinds, W.C. (1999). Aerosol technology: Properties, behavior, and measurement of airborne particles, Wiley, New York.

Howard, J., Huang, A., Li, Z., Tufekci, Z., Zdimal, V., Westhuizen, H.-M. van der, Delft, A. von, Price, A., Fridman, L., Tang, L.H., Tang, V., Watson, G.L., Bax, C.E., Shaikh, R., Questier, F., Hernandez, D., Chu, L.F., Ramirez, C.M., Rimoin, A.W. (2020). Face masks against COVID-19: An evidence review. https://doi.org/10.20944/preprints202004.0203.v1

Hui, D.S.C., Chan, P.K.S. (2010). Severe Acute Respiratory Syndrome and Coronavirus. Infect. Dis. Clin. 24, 619-638. https://doi.org/10.1016/j.idc.2010.04.009

International Commission on Radiological Protection (ICRP) (1994). Human respiratory tract model for radiological protection. Annals of the ICRP, Publication 66. Tarrytown, Elsevier Science Inc., New-York.

Jayaweeraa, M., Pererab, H., Gunawardanaa, B., Manatunge, J. (2020). Transmission of COVID19 virus by droplets and aerosols: A critical review on the unresolved dichotomy. Environ. Res. 188, 109819. https://doi.org/10.1016/j.envres.2020.109819

Jin, Y., Yang, H., Ji, W., Wu, W., Chen, S., Zhang, W., Duan, G. (2020). Virology, epidemiology, pathogenesis, and control of COVID-19. Viruses 12, 372. https://doi.org/10.3390/v12040372

Karl, M., Kukkonen, J., Keuken, M.P., Lützenkirchen, S., Pirjola, L., Hussein, T. (2016). Modelling and measurements of urban aerosol processes on the neighbourhood scale in Rotterdam, Oslo 
and Helsinki. Atmos. Chem. Phys. 16, 4817-4835. https://doi.org/10.5194/acp-16-4817-2016

Kennedy, P.J., Shapiro, M.A. (1980). Further encounters with clear air turbulence in research aircraft. J. Atmos. Sci. 37, 986-993. https://doi.org/10.1175/1520-0469(1980)037\%3C0986:FE WCAT\%3E2.0.CO;2

Kodros, J.K., Volckens, J., Jathar, S.H., Pierce, J.R. (2018). Ambient particulate matter size distributions drive regional and global variability in particle deposition in the respiratory tract. GeoHealth 2, 298-312. https://doi.org/10.1029/2018GH000145

La Rosa, G., Frantini, M., Della, L.S., laconelli, M., Muscillo, M. (2013). Viral infections acquired indoors through airborne, droplet or contact transmission. Ann. Ist. Super. Sanita 49, 124-132. https://doi.org/10.4415/ANN_13_02_03

Leder, K., Newman, D. (2005) Respiratory infections during air travel. Intern. Med. J. 35, 50-55. https://doi.org/10.1111/j.1445-5994.2004.00696.x

Lee, S.A., Hwang, D.C., Li, H.Y., Tsai, C.F., Chen, C.W., Chen, J.K. (2016). Particle size-selective assessment of protection of European standard FFP respirators and surgical masks against particles-tested with human subjects. J. Healthcare Eng. 2016, 8572493. https://doi.org/10.11 55/2016/8572493

Leung, N.H.L., Chu, D.K.W., Shiu, E.Y.C., Chan, K.H., McDevitt, J.J., Hau, B.J.P., Yen, H.L., Li, Y., Ip D.K.M., Peiris, J.S.M., Seto, W.H., Leung, G.M., Milton, D.K., Cowling, B.J. (2020). Respiratory virus shedding in exhaled breath and efficacy of face masks. Nat. Med. 26, 676-680. https://doi.org/10.1038/s41591-020-0843-2

Liu, Y., Ning, Z., Chen, Y., Guo, M., Liu, Yingle, Gali, N.K., Sun, L., Duan, Y., Cai, J., Westerdahl, D., Liu, X., Ho, K., Kan, H., Fu, Q., Lan, K. (2020). Aerodynamic characteristics and RNA concentration of SARS-CoV-2 aerosol in Wuhan hospitals during COVID-19 outbreak. bioRxiv 2020.03.08.982637. https://doi.org/10.1101/2020.03.08.982637

Mittal, R., Ni, R., Seo, J.H. (2020). The flow physics of COVID-19. J. fluid Mech. 894: F2. https://doi.org/10.1017/jfm.2020.330

Morawska, L. (2006). Droplet fate in indoor environments, or can we prevent the spread of infection? Indoor Air 16, 335-347. https://doi.org/10.1111/j.1600-0668.2006.00432.x

Morawska, L., Cao, J. (2020). Airborne transmission of SARS-CoV-2: The world should face the reality. Environ. Int. 139, 105730. https://doi.org/10.1016/j.envint.2020.105730

Pica, N., Bouvier, N.M. (2012). Environmental factors affecting the transmission of respiratory viruses. Curr. Opin. Virol. 2, 90-95. https://doi.org/10.1016/j.coviro.2011.12.003

Pruppacher, H.R., Klett, J.D. (1997). Microphysics of clouds and precipitation. 2nd Edition, Kluwer Academic, Dordrecht.

Ruzer, L.S., Apte, M.G., Sextro, R.G. (2005). Aerosol dose, in: Ruzer, L.S., Harley, N.H. (Eds.), Aerosols handbook. Measurement, Dosimetry and Health Effects.

Setti, L., Passarini, F., De Gennaro, G., Barbieri, P., Perrone, M.G., Piazzalunga, A., Borelli, M., Palmisani, J. (2020a). Is there a plausible role for particulate matter in the spreading of COVID-19 in Northern Italy? BMJ Rapid Responses. https://www.bmj.com/content/368/bmj.m1103/rr

Setti, L., Passarini, F., De Gennaro, G., Barbieri, P., Perrone, M.G., Borelli, M., Palmisani, J., Di Gilio, A., Torboli, V., Fontana, F., Clemente, L., Pallavicini, A., Ruscio, M., Piscitelli, P., Miani, A. (2020b). SARS-Cov-2RNA found on particulate matter of Bergamo in Northern Italy: First evidence. Environ. Res. 188, 109754. https://doi.org/10.1016/j.envres.2020.109754

Steer, B., Gorbunov, B., Muir, R., Ghimire, A., Rowles, J. (2014). Portable planar DMA: Development and tests. Aerosol Sci. Technol. 48, 251-260. https://doi.org/10.1080/02786826.2013.868863

To, K.K.W., Tsang, O.T.Y., Leung, W.S., Tam, A.R., Wu, T.C., Lung, D.C., Yip, C.C.Y., Cai, J.P., Chan, J.M.C., Chik, T.S.H., Lau, D.P.L., Choi, C.Y.C., Chen, L.L., Chan, W.M., Chan, K.H., Ip, J.D., Ng, A.C.K., Poon, R.W.S., Luo, C.T., ... Yuen, K.Y. (2020). Temporal profiles of viral load in posterior oropharyngeal saliva samples and serum antibody responses during infection by SARS-CoV-2: An observational cohort study. Lancet Infect. Dis. 20, 565-574. https://doi.org/10.1016/S14733099(20)30196-1

van Doremalen, N., Bushmaker, T., Morris, D.H., Holbrook, M.G., Gamble, A., Williamson, B.N. Tamin, A., Harcourt, J.L., Thornburg, N.J., Gerber, S.I., Lloyd-Smith, J.O., de Wit, E., Munster, V.J. (2020). Aerosol and Surface Stability of SARS-CoV-2 as Compared with SARS-CoV-1. N. EngI. J. Med. 382, 1564-1567. https://doi.org/10.1056/NEJMc2004973

Vuorinen, V., Aarnio, M., Alava, M., Alopaeus, V., Atanasova, N., Auvinen, M., Balasubramanian, 
N., Bordbar, H., Erästö, P., Grande, R., Hayward, N., Hellsten, A., Hostikka, S., Hokkanen, J., Kaario, O., Karvinen, A., Kivistö, I., Korhonen, M., Kosonen, R., Kuusela, J., ... Österberg, M. (2020). Modelling aerosol transport and virus exposure with numerical simulations in relation to SARS-CoV-2 transmission by inhalation indoors. Saf. Sci. 130, 104866. https://doi.org/10.10 16/j.ssci.2020.104866

World Health Organization (WHO) (2020). Report of the WHO-China Joint Mission on Coronavirus Disease 2019 (COVID-19). World Health Organization. https://www.who.int/docs/defaultsource/coronaviruse/who-china-joint-mission-on-COVID-19-final-report.pdf

Wilson, R. (2004). Turbulent diffusivity in the free atmosphere inferred from MST radar measurements: A review. Ann. Geophys. 22, 3869-3887. https://doi.org/10.5194/angeo-223869-2004

Worldometrics (2020) Fatality Rate (case fatality ratio or CFR) of the Wuhan Coronavirus. https://www.worldometers.info/coronavirus/\#repro

Xiao, J., Shiu, E.Y.C., Gao, H., Wong, J.Y., Fong, M.W., Ryu, S., Cowling, B.J. (2020). Nonpharmaceutical measures for pandemic influenza in nonhealthcare settings-Personal protective and environmental measures. Emerging Infect. Dis. 26, 967-975. https://doi.org/1 0.3201/eid2605.190994

Yang, S., Lee, G.W.M., Chen, C.M., Wu, C.C., Yu, K.P. (2007). The size and concentration of droplets generated by coughing in human subjects. J. Aerosol Med. 20, 484-494. https://doi.org/10.1089/jam.2007.0610

Yu, I.T., Qiu, H., Tse, L.A., Wong, T.W. (2014). Severe acute respiratory syndrome beyond Amoy Gardens: Completing the incomplete legacy. Clin. Infect Dis. 58, 683-686. https://doi.org/10.1 093/cid/cit797

Zayas, G., Chiang, M.C., Wong, E., MacDonald, F., Lange, C.F., Senthilselvan, A., King, M. (2012) Cough aerosol in healthy participants: fundamental knowledge to optimize droplet-spread infectious respiratory disease management. BMC Pulm. Med. 12, 11. https://doi.org/10.1186/ 1471-2466-12-11

Zhao, B., Zhang, Z., Li, X.T. (2005). Numerical study of the transport of droplets or particles generated by respiratory system indoors. Build. Environ. 40, 1032-1039. https://doi.org/10.10 16/j.buildenv.2004.09.018 